\title{
Systematic Evaluation of Chromatographic Parameters for Isoquinoline Alkaloids on XB-C18 Core-Shell Column Using Different Mobile Phase Compositions
}

\author{
Ireneusz Sowa, ${ }^{1}$ Sylwia Zielińska, ${ }^{2}$ Jan Sawicki, ${ }^{1}$ Anna Bogucka-Kocka, ${ }^{3}$ \\ Michał Staniak, ${ }^{1}$ Ewa Bartusiak-Szcześniak, ${ }^{1}$ Maja Podolska-Fajks, ${ }^{1}$ \\ Ryszard Kocjan, ${ }^{1}$ and Magdalena Wójciak-Kosior ${ }^{10}{ }^{1}$ \\ ${ }^{1}$ Department of Analytical Chemistry, Medical University of Lublin, Chodźki 4a, 20-093 Lublin, Poland \\ ${ }^{2}$ Department of Pharmaceutical Biology, Wroclaw Medical University, Borowska 211, 50-556 Wroclaw, Poland \\ ${ }^{3}$ Department of Biology with Genetics, Medical University of Lublin, Chodźki 4a, 20-093 Lublin, Poland \\ Correspondence should be addressed to Magdalena Wójciak-Kosior; kosiorma@wp.pl
}

Received 31 August 2017; Accepted 25 October 2017; Published 20 February 2018

Academic Editor: Adam Voelkel

Copyright (c) 2018 Ireneusz Sowa et al. This is an open access article distributed under the Creative Commons Attribution License, which permits unrestricted use, distribution, and reproduction in any medium, provided the original work is properly cited.

\begin{abstract}
Chelidonium majus L. is a rich source of isoquinoline alkaloids with confirmed anti-inflammatory, choleretic, spasmolytic, antitumor, and antimicrobial activities. However, their chromatographic analysis is difficult because they may exist both in charged and uncharged forms and may result in the irregular peak shape and the decrease in chromatographic system efficacy. In the present work, the separation of main C. majus alkaloids was optimized using a new-generation XB-C18 endcapped core-shell column dedicated for analysis of alkaline compounds. The influence of organic modifier concentration, addition of salts, and $\mathrm{pH}$ of eluents on chromatographic parameters such as retention, resolution, chromatographic plate numbers, and peak asymmetry was investigated. The results were applied to elaborate the optimal chromatographic system for simultaneous quantification of seven alkaloids from the root, herb, and fruit of C. majus.
\end{abstract}

\section{Introduction}

Isoquinoline alkaloids such as coptisine, allocryptopine, protopine, berberine, chelidonine, sanguinarine, and chelerythrine are the main constituents of Chelidonium majus L. responsible for biological properties of the plant. They have analgesic, antispasmodic, antibacterial, antiviral, and antifungal activities. Moreover, they show cytotoxic and antiproliferative effects against various types of cancer cell lines [1-4]. Because of the broad spectrum of action, C. majus alkaloids are a subject of interest for pharmacology and toxicology; therefore, the effective analytical methods for their investigation are still being developed. Spectrophotometry $[5,6]$, capillary electrophoresis $[7,8]$, and thin-layer chromatography [9-12] have been used for this purpose; however, high-performance liquid chromatography is the most common for qualitative and quantitative analyses of $C$. majus [5, 13-17].

Due to the durability, silica-based RP-18 stationary phases are widely used for HPLC separation of plant extracts $[18,19]$; however, RP chromatography of alkaloids is rather difficult because they may exist both as free bases and charged forms. Cationic forms strongly interact with residual silanol groups of the RP-type stationary phase and cause the occurrence of the dual retention mechanism (RP and ion-exchange retention mechanism) and result in the peak tailing, irreproducible retention, and poor system efficiency [20].

Due to the basic character of isoquinoline alkaloids, it would be preferable to conduct chromatographic separation at alkaline $\mathrm{pH}$ to avoid their ionization; however, silica-based adsorbents are unstable at this condition [21]. 
TABLE 1: The comparison of retention times and peak resolutions of investigated alkaloids in $20-25 \%$ of acetonitrile in water at different $\mathrm{pH}$ and ammonium acetate concentrations.

\begin{tabular}{lccccccccccccccccccc}
\hline & \multicolumn{3}{c}{$20 \% \mathrm{ACN}, \mathrm{pH}=3$} & \multicolumn{3}{c}{$20 \% \mathrm{ACN}, \mathrm{pH}=4$} & \multicolumn{3}{c}{$25 \% \mathrm{ACN}, \mathrm{pH}=3$} & \multicolumn{3}{c}{$25 \% \mathrm{ACN}, \mathrm{pH}=4$} \\
& \multicolumn{2}{c}{$20 \mathrm{mM}$} & \multicolumn{2}{c}{$10 \mathrm{mM}$} & \multicolumn{2}{c}{$20 \mathrm{mM}$} & \multicolumn{1}{c}{$10 \mathrm{mM}$} & \multicolumn{2}{c}{$20 \mathrm{mM}$} & \multicolumn{2}{c}{$10 \mathrm{mM}$} & \multicolumn{2}{c}{$20 \mathrm{mM}$} & \multicolumn{2}{c}{$10 \mathrm{mM}$} \\
& $t_{R}$ & $R_{S}$ & $t_{R}$ & $R_{S}$ & $t_{R}$ & $R_{S}$ & $t_{R}$ & $R_{S}$ & $t_{R}$ & $R_{S}$ & $t_{R}$ & $R_{S}$ & $t_{R}$ & $R_{S}$ & $t_{R}$ & $R_{S}$ \\
\hline Protopine & 10.94 & 5.38 & 11.49 & 6.08 & 13.16 & 5.79 & 13.91 & 7.25 & 6.54 & 4.07 & 6.66 & 4.07 & 7.75 & 4.20 & 7.72 & 4.55 \\
Allocryptopine & 13.40 & 1.36 & 14.17 & 1.45 & 16.81 & 3.47 & 17.06 & 3.35 & 7.61 & 1.25 & 7.73 & 1.43 & 8.89 & 3.98 & 9.03 & 3.23 \\
Chelidonine & 14.07 & 4.11 & 14.90 & 3.88 & 18.79 & 2.68 & 19.29 & 3.05 & 7.97 & 2.56 & 8.17 & 2.60 & 10.07 & 1.21 & 10.07 & 1.29 \\
Coptisine & 16.02 & 13.65 & 16.84 & 14.26 & 20.35 & 14.18 & 21.03 & 14.95 & 8.73 & 8.72 & 8.92 & 9.41 & 10.5 & 9.57 & 10.55 & 9.08 \\
Sanguinarine & 24.58 & 5.62 & 26.39 & 5.45 & 33.71 & 4.59 & 37.27 & 4.07 & 11.76 & 5.65 & 12.11 & 5.70 & 14.8 & 5.38 & 14.78 & 5.11 \\
Berberine & 28.96 & 17.00 & 31.01 & 17.22 & 39.12 & 16.82 & 42.27 & 18.23 & 14.01 & 12.67 & 14.43 & 12.79 & 17.58 & 13.25 & 17.51 & 12.62 \\
Chelerythrine & 47.54 & - & 51.73 & - & 66.91 & - & 74.71 & - & 20.45 & - & 21.26 & - & 26.45 & - & 26.28 & - \\
\hline
\end{tabular}

Different approaches may be used to eliminate these problems. Alkaline additives to mobile phases, mostly organic amines such as diethylamine, triethylamine, or dimethyloctylamine, are applied to suppress the ionization of the analyte and as silanol blockers [14, 15]. Addition of anionic ion-pairing reagents, for example, sodium dodecyl sulphate or salts (e.g., ammonium acetate, ammonium formate, and sodium phosphate) is also used to improve the chromatographic separation $[5,13,17,22]$. On the other hand, the silanol-masking effect may be achieved by additional modification of the sorbent surface, for example, endcapping $[23,24]$.

XB-C18 sorbent is relatively new column filling with trimethylsilane endcapping and additional isobutyl chains. In the present work, an XB reversed-phase column was used to separate the isoquinoline alkaloids typically found in the C. majus extract. The influence of organic modifier concentration, addition of salts, and $\mathrm{pH}$ of eluents on chromatographic parameters such as retention, resolution, chromatographic plate numbers, and peak asymmetry was investigated. The results were applied to elaborate the optimal chromatographic system for simultaneous quantification of alkaloids from the root, herb, and fruit of C. majus.

\section{Experimental}

2.1. Chemicals and Reagents. Alkaloid standards such as protopine (Prot), allocryptopine (All), berberine (Berb), chelidonine (Che), chelerythrine (Chele), and sanguinarine (Sang) were purchased from Sigma (St. Louis, MO) and coptisine (Cop) from ChromaDex (USA). Ammonium acetate, ammonium formate, acetic acid, formic acid, HPLCgrade methanol $(\mathrm{MeOH})$, and acetonitrile $(\mathrm{ACN})$ were from Merck (Darmstadt, Germany). Water was deionized and purified by ULTRAPURE Millipore Direct-QVR 3UV-R (Merck, Darmstadt, Germany).

2.2. High-Performance Liquid Chromatography. Chromatography was carried out using a VWR Hitachi Chromaster 600 chromatograph (Merck, Darmstadt, Germany) with a spectrophotometric detector (DAD) and EZChrom Elite software (Merck).
The samples were analyzed on an XB-C18 reversedphase core-shell column (Kinetex, Phenomenex, Aschaffenburg, Germany) $(25 \mathrm{~cm} \times 4.6 \mathrm{~mm}$ i.d., $5 \mu \mathrm{m}$ particle size $)$, at a temperature of $25^{\circ} \mathrm{C}$ and an eluent flow rate of $1 \mathrm{~mL} / \mathrm{min}$.

Chromatograms were recorded in the range of wavelength from 220 to $400 \mathrm{~nm}$. The identity of compounds in plant extracts was confirmed by comparison of retention times and spectra with corresponding standards. Peak homogeneity was established comparing the spectrum recorded at the three peak sections upslope, apex, and downslope with the reference spectrum. Additionally, the chromatographic fractions eluted at the retention time characteristic for the investigated alkaloids were collected using a Foxy R1 fraction collector (Teledyne Isco, Lincoln, USA), and their identity was confirmed by direct injection mass spectrometry (micrOTOF-Q II, Bruker Daltonics, Bremen, Germany) using Compass DataAnalysis software version 4.1.

2.3. Sample Preparation. The extraction conditions were based on literature [13]. The root, leaf, and fruit of $C$. majus $(1 \mathrm{~g})$ were extracted in ultrasonic bath $(3 \times 15 \mathrm{~min})$ with $10 \mathrm{~mL}$ of methanol acidified with $0.05 \mathrm{M} \mathrm{HCl}$. Subsequently, the extracts were combined, evaporated to dryness, and dissolved in $20 \mathrm{~mL}$ of methanol.

\section{Results and Discussion}

Sufficient resolution between neighbouring peaks, symmetric peaks, and narrow peaks are the most important for the optimal chromatographic system. A stationary phase and a mobile phase have a crucial impact on these parameters. In our work, different variants of eluent compositions were tested for their suitability in HPLC of isoquinoline alkaloids on a new-generation XB-C18 endcapped core-shell column. The influence of the three variables: concentration of the organic modifier, salt, and $\mathrm{pH}$ on resolution $\left(R_{S}\right)$, peak asymmetry $\left(A_{S}\right)$, and system efficacy $(N$-theoretical plate numbers) for methanol/water and acetonitrile/water solvent systems was investigated.

3.1. Optimization of Chromatographic Condition. The chromatographic parameters were established in the range 

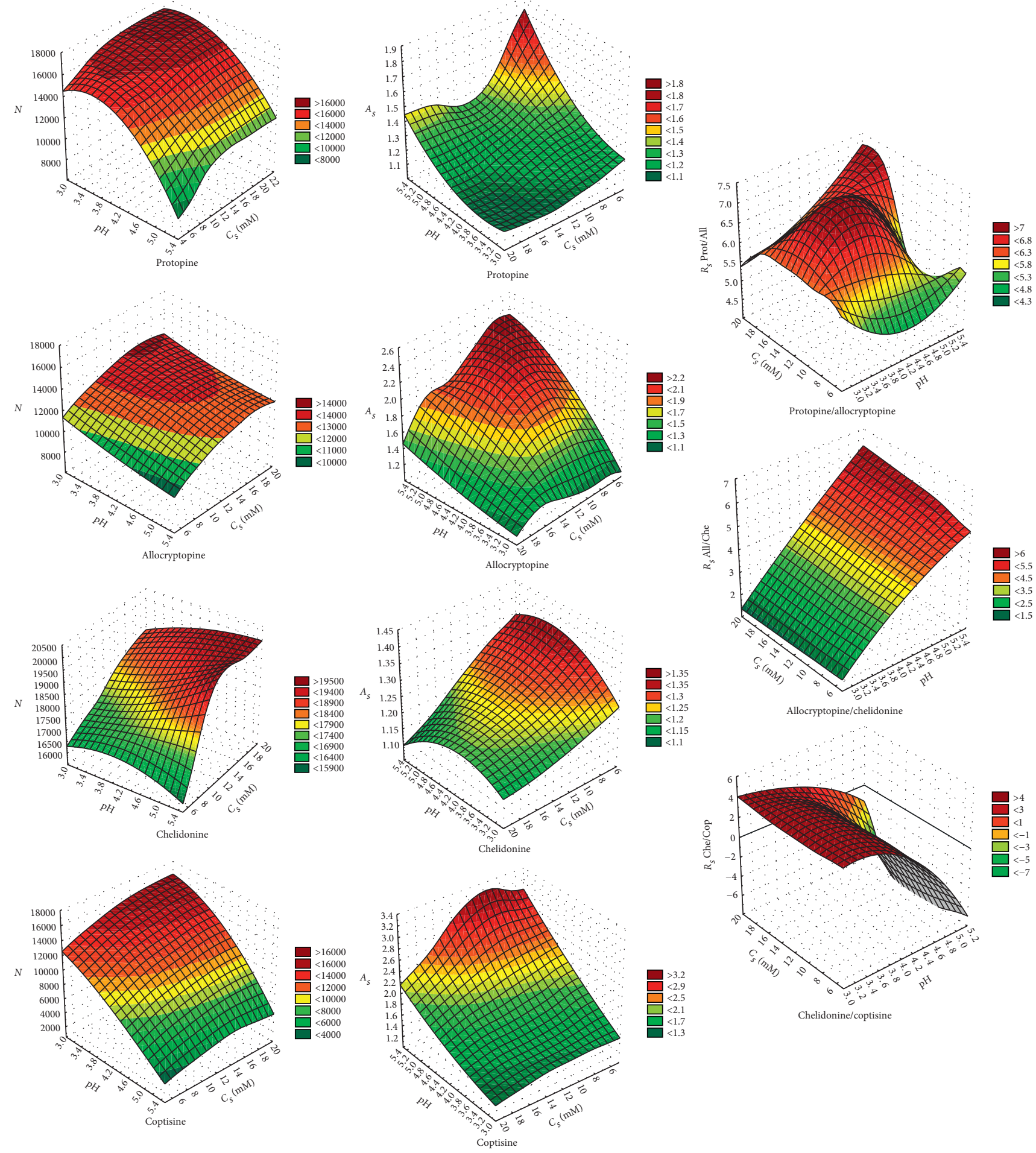

FiguRE 1: The relationship between theoretical plate numbers $(N)$, peak asymmetry $\left(A_{s}\right)$, resolution $\left(R_{s}\right)$, and pH/ammonium acetate concentration.

of $20-40 \%$ of acetonitrile (ACN) and $30-40 \%$ of methanol $(\mathrm{MeOH})$ in water. Acid (acetic or formic) to obtain appropriate $\mathrm{pH}(3-5.5)$ and salt (ammomium acetate or ammonium formate) at the concentration range 5-20 $\mathrm{mM}$ were added to tested eluents because blocking and suppressing the ionization of residual silanol groups of the stationary phase were necessary to avoid peak splitting or broadening of basic compounds.

In $\mathrm{ACN} /$ water and $\mathrm{MeOH} /$ water systems, the amount of organic modifier strongly influence the alkaloid retention. 
TABLE 2: The comparison of retention times and peak resolutions of investigated alkaloids in 35\% of methanol in water at different pH and ammonium acetate concentrations.

\begin{tabular}{|c|c|c|c|c|c|c|c|c|}
\hline & \multicolumn{4}{|c|}{$\mathrm{pH}=3$} & \multicolumn{4}{|c|}{$\mathrm{pH}=4$} \\
\hline & \multicolumn{2}{|c|}{$20 \mathrm{mM}$} & \multicolumn{2}{|c|}{$10 \mathrm{mM}$} & \multicolumn{2}{|c|}{$20 \mathrm{mM}$} & \multicolumn{2}{|c|}{$10 \mathrm{mM}$} \\
\hline & $t_{R}$ & $R_{S}$ & $t_{R}$ & $R_{S}$ & $t_{R}$ & $R_{S}$ & $t_{R}$ & $R_{S}$ \\
\hline Protopine & 8.05 & 0.63 & 8.34 & 0.77 & 10.67 & 1.12 & 10.51 & 1.10 \\
\hline Allocryptopine & 8.47 & 0.96 & 8.92 & 0.76 & 11.56 & 2.25 & 11.23 & 2.36 \\
\hline Chelidonine & 9.11 & 1.18 & 9.49 & 1.18 & 13.37 & 0.08 & 13.15 & 0.30 \\
\hline Coptisine & 9.68 & 10.60 & 10.18 & 10.02 & 13.43 & 10.48 & 13.37 & 12.94 \\
\hline Berberine & 15.88 & 2.57 & 17.23 & 2.75 & 23.82 & 7.93 & 23.9 & 14.47 \\
\hline Sanguinarine & 17.73 & 13.12 & 19.47 & 13.26 & 36.85 & 6.21 & 48.31 & 5.71 \\
\hline Chelerythrine & 29.85 & - & 33.4 & - & 50.16 & - & 63.02 & - \\
\hline
\end{tabular}

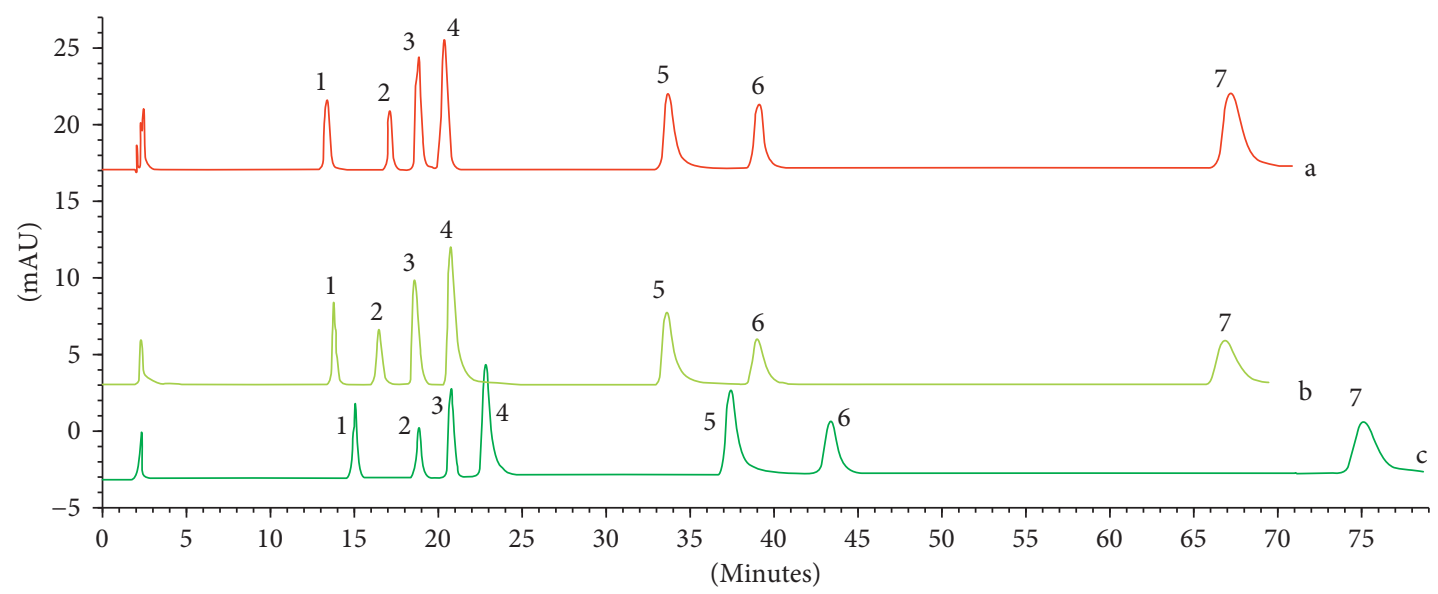

FIGURE 2: Exemplary chromatograms of the standard mixture obtained at (a) acetonitrile and $10 \mathrm{mM}$ water solution of ammonium formate adjusted to $\mathrm{pH} 4$ with formic acid (20:80, v/v), (b) acetonitrile and $20 \mathrm{mM}$ water solution of ammonium acetate adjusted to $\mathrm{pH} 4$ with acetic acid $(20: 80, \mathrm{v} / \mathrm{v})$, and (c) acetonitrile and $10 \mathrm{mM}$ water solution of ammonium acetate adjusted to $\mathrm{pH} 4 \mathrm{with}$ acetic acid (20:80, v/v). (1) protopine, (2) allocryptopine, (3) chelidonine, (4) coptisine, (5) sanguinarine, (6) berberine, and (7) chelerythrine.

Taking into consideration the resolution, the total separation of investigated compounds was obtained for concentration of $20 \% \mathrm{ACN}$ in the whole tested $\mathrm{pH}$ and salt concentration range. At $25 \%$ of $\mathrm{ACN}$, the compound $\mathrm{All} / \mathrm{Che}($ at $\mathrm{pH} \geq 4$ ) or Che/Cop (at $\mathrm{pH} \leq 4)$ partially coeluted. The exemplary $R_{s}$ values are given in Table 1.

In higher concentrations, the majority of compounds were eluted below $10 \mathrm{~min}$ ( $k$ values for protopine, allocryptopine, and chelidonine were lower than 1 ), and the resolution was poor (Table S1). The concentration of ammonium acetate and $\mathrm{pH}$ also affected the alkaloid retention; at lower $\mathrm{pH}$ values and at higher salt amounts, retention times were shortened. Moreover, efficiency of the system $(N)$, symmetry of peaks $\left(A_{s}\right)$, and resolution $\left(R_{s}\right)$ strongly depended on these variables. $N, A_{s}$, and $R_{s}$ values versus $\mathrm{pH}$ and salt concentration are presented in Figure 1 and Figure S1.

As can be seen, at $\mathrm{pH} 5$ and at concentration of salt $5 \mathrm{mM}$, theoretical plate number decreased and peak asymmetry increased significantly, and it resulted in the peak broadening and decreased peak resolution. In contrast to salt concentration, $\mathrm{pH}$ had a major impact on $R_{s}$. Resolution between Che/Cop, Cop/Sang, and Sang/Berb increased at lower $\mathrm{pH}$; in turn, for All/Che, the opposite effect occurred. Moreover, the change of elution order was observed for chelidonine and coptisine at $\mathrm{pH} 5$.

Methanol showed lower elution strength, and the concentration in the range of $30-35 \%$ was required to obtain the elution of alkaloids at a reasonable time. Moreover, the order of elution strongly depended on $\mathrm{pH}$ and amount of organic modifier and salt (Table 2 and Table S2).

As can be seen, no composition of mobile phases provided sufficient separation within compounds with weaker retention such as protopine, allocryptopine, chelidonine, and coptisine, and all tested chromatographic parameters were worse for methanol/water than for acetonitrile/water eluents.

In further experiments, ammonium acetate/acetic acid in ACN/water eluents was replaced by ammonium formate/formic acid; however, it had a minor impact on chromatographic parameters. The $R_{s}$ values and retention times did not differ significantly, and only a slight increase in system efficacy (narrower peaks) was observed. Exemplary chromatograms of the standard mixture obtained at various mobile phase compositions are shown in Figure 2. 


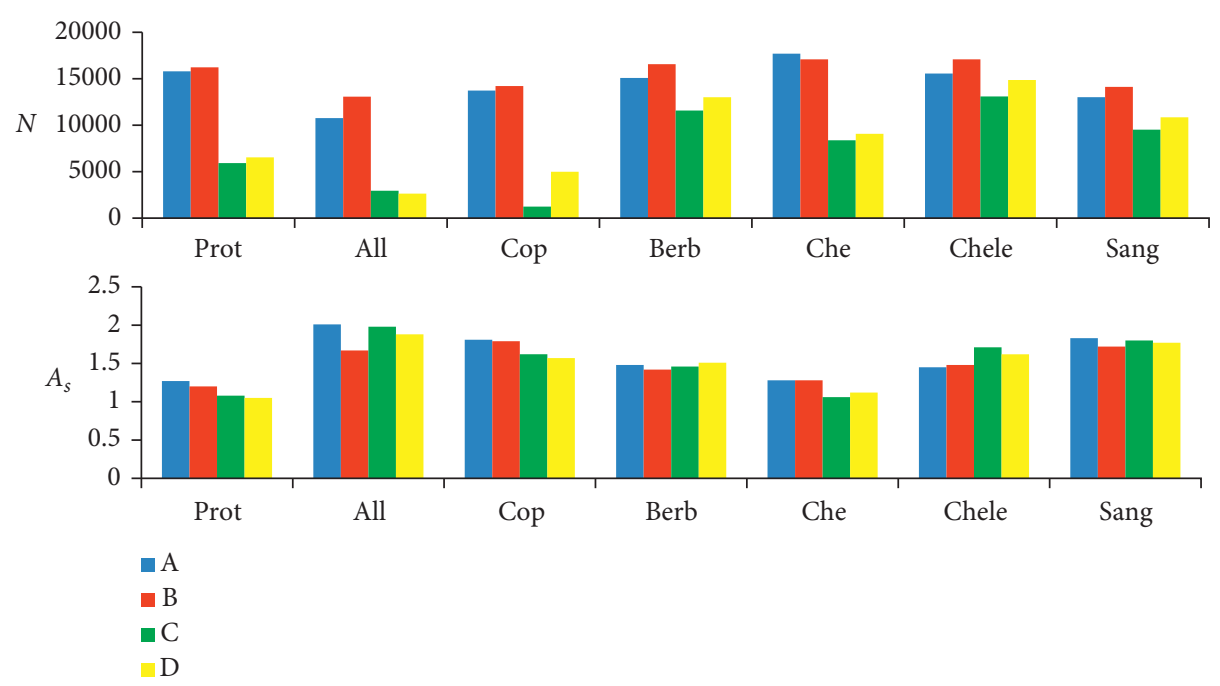

FIGURE 3: Comparison of theoretical plate numbers and peak asymmetry obtained on XB-C18 column for $20 \%$ of acetonitrile and $30 \%$ of methanol: (A) acetonitrile and $10 \mathrm{mM}$ water solution of ammonium acetate adjusted to $\mathrm{pH} 4$ with acetic acid; (B) acetonitrile and $10 \mathrm{mM}$ water solution of ammonium formate adjusted to $\mathrm{pH} 4$ with formic acid; (C) methanol and $10 \mathrm{mM}$ water solution of ammonium acetate adjusted to $\mathrm{pH} 3$ with acetic acid; (D) methanol and $10 \mathrm{mM}$ water solution of ammonium acetate adjusted to $\mathrm{pH} 4 \mathrm{with}$ acetic acid.

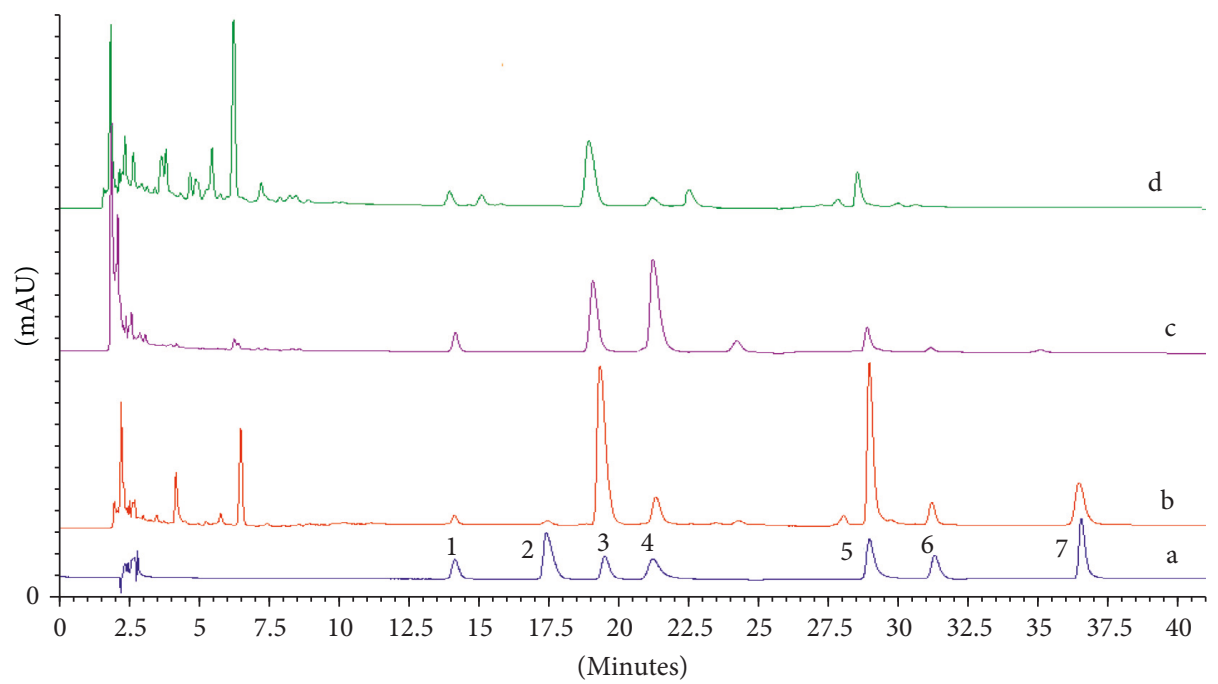

Figure 4: Example of an HPLC-DAD chromatogram of extracts from different parts of C. majus: (b) roots, (c) fruits, and (d) herbs and (a) standards of investigated alkaloids: (1) protopine, (2) allocryptopine, (3) chelidonine, (4) coptisine, (5) sanguinarine, (6) berberine, and (7) chelerythrine.

The comparison of $N$ and $A_{s}$ for various mobile phase compositions is presented in Figure 3.

Based on the obtained results, acetonitrile at concentration of $20 \%$ and water at $\mathrm{pH} 3-4$ with addition of 10-20 mM ammonium acetate or ammonium formate were considered as optimal for isoquinoline alkaloid separation on an XB-C18 core-shell column.

A lot of chromatographic systems for RP separation of isoquinoline alkaloids in C. majus were described in literature; however, most of them were more complicated $[14,15,22]$ or did not provide sufficient separation for quantitative analysis [25]. Due to additional modification of endcapped octadecyl silica by isobutyl chains in the XB-C18 stationary phase, the interaction of the basic analyte with residual silanol decreased significantly. It allowed to conduct chromatographic separation using milder $\mathrm{pH}$ and lower amount of salt addition compared to eluents proposed in literature [13], and it is beneficial for the HPLC system.

3.2. Chromatographic Analysis of C. majus Extracts. Chromatography of the C. majus extract was carried out using the mobile phase consisting of ACN (solvent A) and $10 \mathrm{mM}$ water solution of ammonium acetate adjusted to $\mathrm{pH} 4$ with acetic acid (solvent $\mathrm{B})(20: 80, \mathrm{v} / \mathrm{v})$. High $R_{s}$ values between coptisine and sanguinarine allowed to use the simple 
TABLE 3: The data used for identification of the investigated compounds.

Retention time (min)
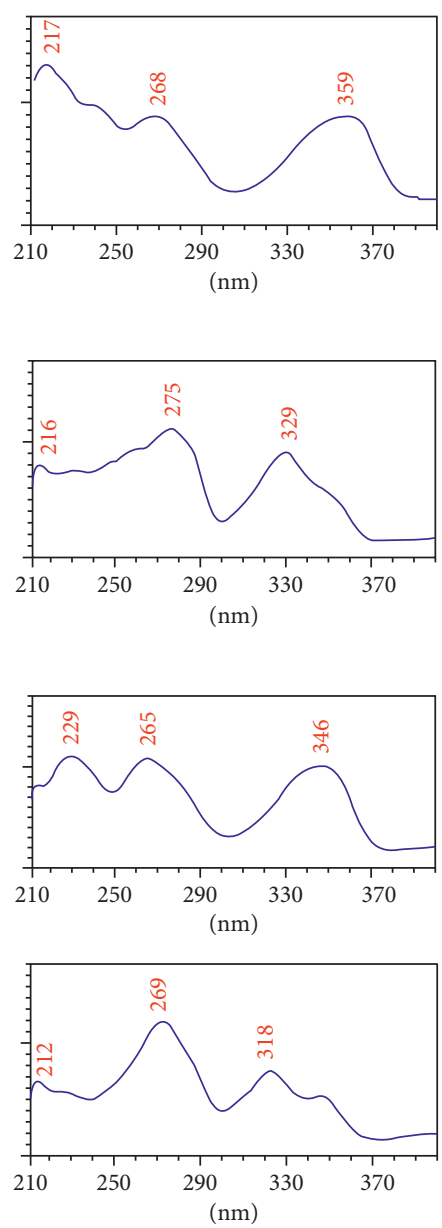
TABLE 4: The content of investigated alkaloids $(\mathrm{mg} / 100 \mathrm{~g} \pm \mathrm{SD})$ in different parts of C. majus.

\begin{tabular}{lccc}
\hline & Root & Herb & Fruit \\
\hline Protopine & $15.7 \pm 1.1$ & $20.2 \pm 1.6$ & $22.4 \pm 2.0$ \\
Allocryptopine & $11.4 \pm 0.8$ & - & - \\
Chelidonine & $140.1 \pm 10.4$ & $65.2 \pm 5.1$ & $57.4 \pm 5.1$ \\
Coptisine & $50.1 \pm 4.1$ & $20.8 \pm 1.5$ & $247.2 \pm 20.9$ \\
Sanguinarine & $311.6 \pm 22.4$ & $29.8 \pm 2.1$ & $20.1 \pm 1.9$ \\
Berberine & $52.7 \pm 3.9$ & $0.8 \pm 0.1$ & $10.4 \pm 0.9$ \\
Chelerythrine & $100.3 \pm 7.8$ & $<$ LOQ & $<$ LOQ \\
\hline
\end{tabular}

gradient program to shorten the total time of analysis. After $20 \mathrm{~min}$, the elution strength of the mobile phase was increased to accelerate elution of strongly retained sanguinarine, berberine, and chelerythrine. The gradient program was as follows: A $20 \%$ and B $80 \%$ during $0-20 \mathrm{~min}$, A $25 \%$ and B $75 \%$ during $20-27 \mathrm{~min}$, and A $30 \%$ and B $70 \%$ during $27-40 \mathrm{~min}$. The obtained chromatograms are presented in Figure 4.

The data used for identification of the investigated compounds are given in Table 3.

The results of quantitative determination of isoquinoline alkaloids in the root, leaf, and fruit of C. majus are given in Table 4, and validation parameters are summarized in Table S3.

\section{Conflicts of Interest}

The authors declare that there are no conflicts of interest regarding the publication of this paper.

\section{Supplementary Materials}

Table S1: the comparison of retention times and peak resolutions of investigated alkaloids in 30\% of acetonitrile in water at different $\mathrm{pH}$ and ammonium acetate concentration. Table S2: the comparison of retention times and peak resolutions of investigated alkaloids in $30 \%$ of methanol in water at different $\mathrm{pH}$ and ammonium acetate concentration. Table S3: calibration data for quantification of investigated alkaloids. Figure S1: the relationship between theoretical plate numbers $(\mathrm{N})$, peak asymmetry (As), resolution (Rs) and $\mathrm{pH} / \mathrm{ammonium}$ acetate concentration. (Supplementary Materials)

\section{References}

[1] M. L. Colombo and E. Bosisio, "Pharmacological activities of Chelidonium majus L. (Papaveraceae)," Pharmacological Research, vol. 33, no. 2, pp. 127-134, 1996.

[2] M. Gilca, L. Gaman, E. Panait, I. Stoian, and V. Atanasiu, "Chelidonium majus-an integrative review: traditional knowledge versus modern findings," Forschende Komplementärmedizin, vol. 17, no. 5, pp. 241-248, 2010.

[3] R. Havelek, M. Seifrtova, K. Kralovec et al., "Comparative cytotoxicity of chelidonine and homochelidonine, the dimethoxy analogues isolated from Chelidonium majus L. (Papaveraceae), against human leukemic and lung carcinoma cells," Phytomedicine, vol. 23, no. 3, pp. 253-266, 2016.

[4] I. R. Capistrano, A. Wouters, F. Lardon, C. Gravekamp, S. Apers, and L. Pieters, "In vitro and in vivo investigations on the antitumour activity of Chelidonium majus," Phytomedicine, vol. 22, no. 14, pp. 1279-1287, 2015.

[5] K. Seidler-Łożykowska, B. Kędzia, J. Bocianowski et al., "Content of alkaloids and flavonoids in celandine (Chelidonium majus L.) herb at selected developmental phases," Acta Scientiarum Polonorum Hortorum Cultus, vol. 16, no. 3, pp. 161-172, 2017.

[6] M. Then, K. Szentmihályi, A. Sárközi, V. Illés, and E. Forgács, "Effect of sample handling on alkaloid and mineral content of aqueous extracts of greater celandine (Chelidonium majus L.)," Journal of Chromatography A, vol. 889, no. 1-2, pp. 69-74, 2000.

[7] Q. Zhou, Y. Liu, X. Wang, and X. Di, "Microwave-assisted extraction in combination with capillary electrophoresis for rapid determination of isoquinoline alkaloids in Chelidonium majus L.," Talanta, vol. 99, pp. 932-938, 2012.

[8] M. Kulp and O. Bragina, "Capillary electrophoretic study of the synergistic biological effects of alkaloids from Chelidonium majus L. in normal and cancer cells," Analytical and Bioanalytical Chemistry, vol. 405, no. 10, pp. 3391-3397, 2013.

[9] W. Jesionek, E. Fornal, B. Majer-Dziedzic, Á. M. Móricz, W. Nowicky, and I. M. Choma, "Investigation of the composition and antibacterial activity of Ukrain $^{\mathrm{TM}}$ drug using liquid chromatography techniques," Journal of Chromatography $A$, vol. 1429, pp. 340-347, 2016.

[10] I. Malinowska, M. Studziński, H. Malinowski, and M. Gadzikowska, "Retention and separation changes of ternary and quaternary alkaloids from Chelidonium majus L. by TLC under the influence of external magnetic field," Chromatographia, vol. 80, no. 6, pp. 923-930, 2017.

[11] Á. Sárközi, G. Janicsák, L. Kursinszki, and Á. Kéry, “Alkaloid composition of Chelidonium majus L. studied by different chromatographic techniques," Chromatographia, vol. 63, no. S13, pp. 81-86, 2006.

[12] A. Bogucka-Kocka and D. Zalewski, "Qualitative and quantitative determination of main alkaloids of Chelidonium majus L. using thin-layer chromatographic-densitometric method," Acta Chromatographica, vol. 29, no. 3, pp. 385-397, 2017.

[13] L. Kursinszki, Á. Sárközi, Á. Kéry, and É. Szöke, "Improved RP-HPLC method for analysis of isoquinoline alkaloids in extracts of Chelidonium majus," Chromatographia, vol. 63, no. S13, pp. S131-S135, 2006.

[14] H. Wu and L. Du, "Ionic liquid-liquid phase microextraction for the sensitive determination of sanguinarine and chelerythrine in Chinese herbal medicines and human urine," Journal of Liquid Chromatography \& Related Technologies, vol. 35, no. 12, pp. 1662-1675, 2012.

[15] J. Paulsen, M. Yahyazadeh, S. Hänsel, M. Kleinwächter, K. Ibrom, and D. Selmar, "13,14-dihydrocoptisine-the genuine alkaloid from Chelidonium majus," Phytochemistry, vol. 111, pp. 149-153, 2015.

[16] C. Grosso, F. Ferreres, A. Gil-Izquierdo et al., "Box-Behnken factorial design to obtain a phenolic-rich extract from the aerial parts of Chelidonium majus L.," Talanta, vol. 130, pp. 128-136, 2014.

[17] A. Borghini, D. Pietra, C. di Trapani, P. Madau, G. Lubinu, and A. M. Bianucci, "Data mining as a predictive model for Chelidonium majus extracts production," Industrial Crops and Products, vol. 64, pp. 25-32, 2015.

[18] X. Wei, H. Shen, L. Wang, Q. Meng, and W. Liu, "Analyses of total alkaloid extract of Corydalis yanhusuo by comprehensive $\mathrm{RP} \times \mathrm{RP}$ liquid chromatography with $\mathrm{pH}$ 
difference," Journal of Analytical Methods in Chemistry, vol. 2016 Article ID 9752735, 8 pages, p. 8, 2016.

[19] N. Yu, C. He, G. Awuti, C. Zeng, J. Xing, and W. Huang, "Simultaneous determination of six active compounds in Yixin Badiranjibuya granules, a traditional Chinese medicine, by RP-HPLC-UV method," Journal of Analytical Methods in Chemistry, Article ID 974039, vol. 2015, p. 9, 2015.

[20] F. Gritti and G. Guiochon, "Physical origin of peak tailing on $\mathrm{C}_{18}$-bonded silica in reversed-phase liquid chromatography," Journal of Chromatography A, vol. 1028, no. 1, pp. 75-88, 2004.

[21] J. J. Kirkland, J. B. Adams Jr., M. A. van Straten, and H. A. Claessens, "Bidentate silane stationary phases for reversed-phase high-performance liquid chromatography," Analytical Chemistry, vol. 70, no. 20, pp. 4344-4352, 1998.

[22] N. A. Gañán, A. M. A. Dias, F. Bombaldi et al., "Alkaloids from Chelidonium majus L.: Fractionated supercritical $\mathrm{CO}_{2}$ extraction with co-solvents," Separation and Purification Technology, vol. 165, pp. 199-207, 2016.

[23] F. Gritti and G. Guiochon, "Chromatographic estimate of the degree of surface heterogeneity of reversed-phase liquid chromatography packing materials. II-endcapped monomeric C18-bonded stationary phase," Journal of Chromatography A, vol. 1103, no. 1, pp. 57-68, 2006.

[24] F. Gritti and G. Guiochon, "Influence of the degree of coverage of $\mathrm{C}_{18}$-bonded stationary phases on the mass transfer mechanism and its kinetics," Journal of Chromatography A, vol. 1128, no. 1-2, pp. 45-60, 2006.

[25] H. Prosen and B. Pendry, "Determination of shelf life of Chelidonium majus, Sambucus nigra, Thymus vulgaris and Thymus serpyllum herbal tinctures by various stability-indicating tests," Phytochemistry Letters, vol. 16, pp. 311-323, 2016. 

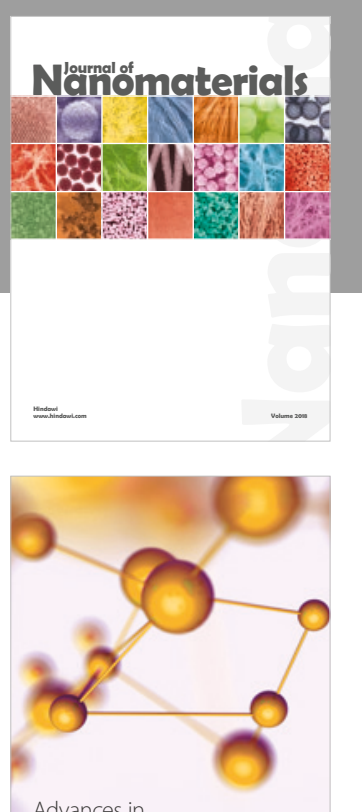

Physical Chemistry
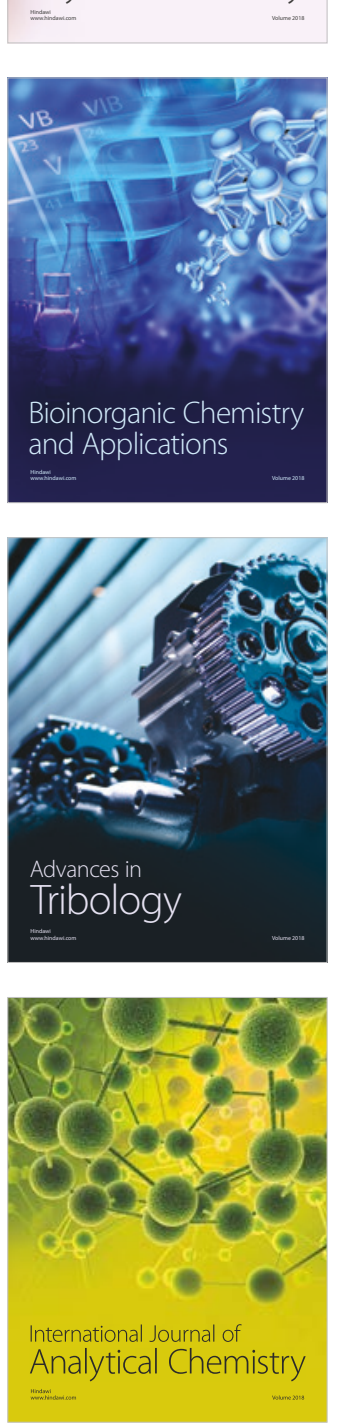

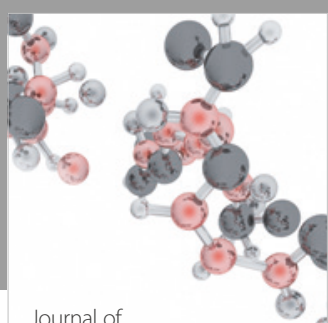

Analytical Methods

in Chemistry

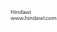

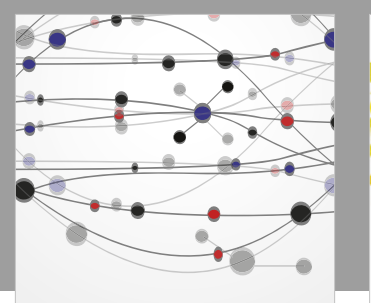

The Scientific World Journal

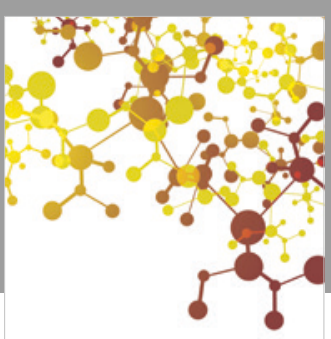

Journal of

Applied Chemistry
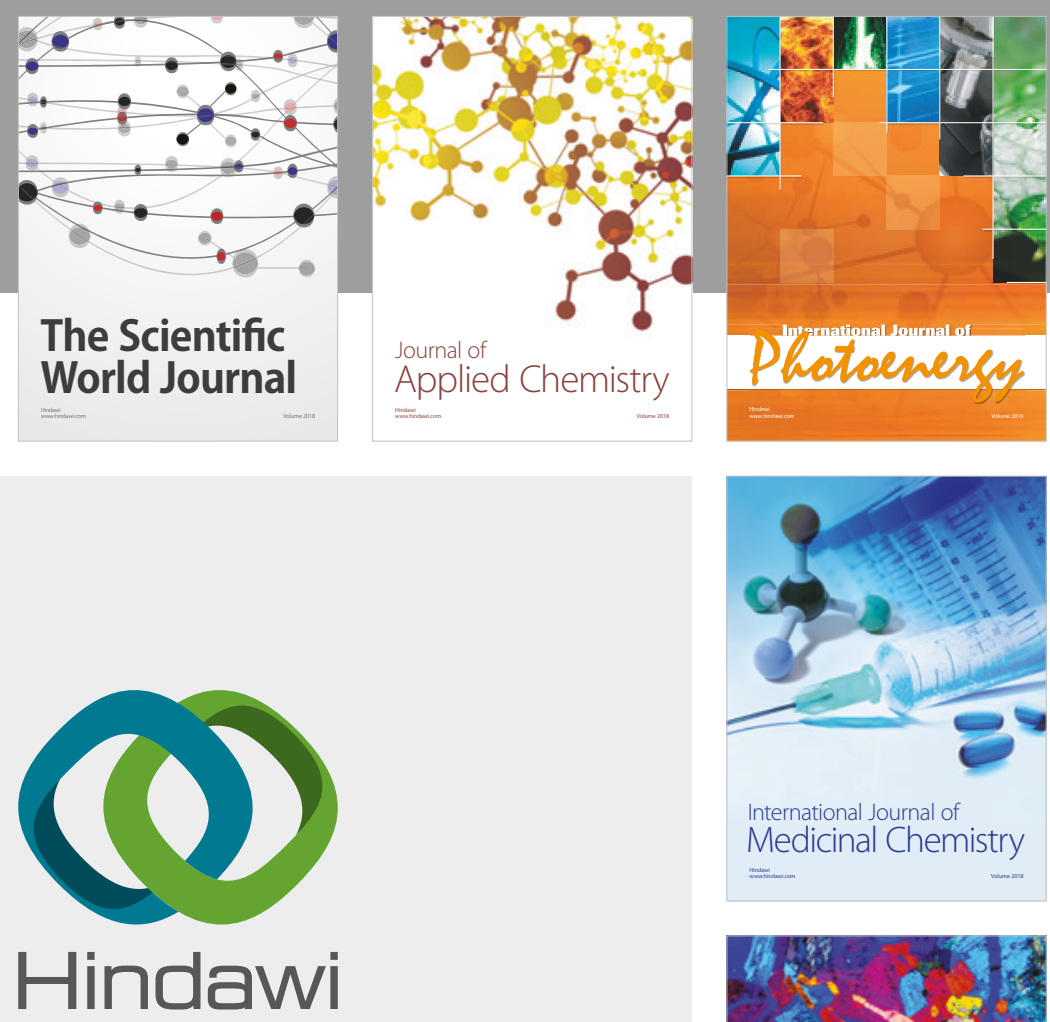

Submit your manuscripts at

www.hindawi.com
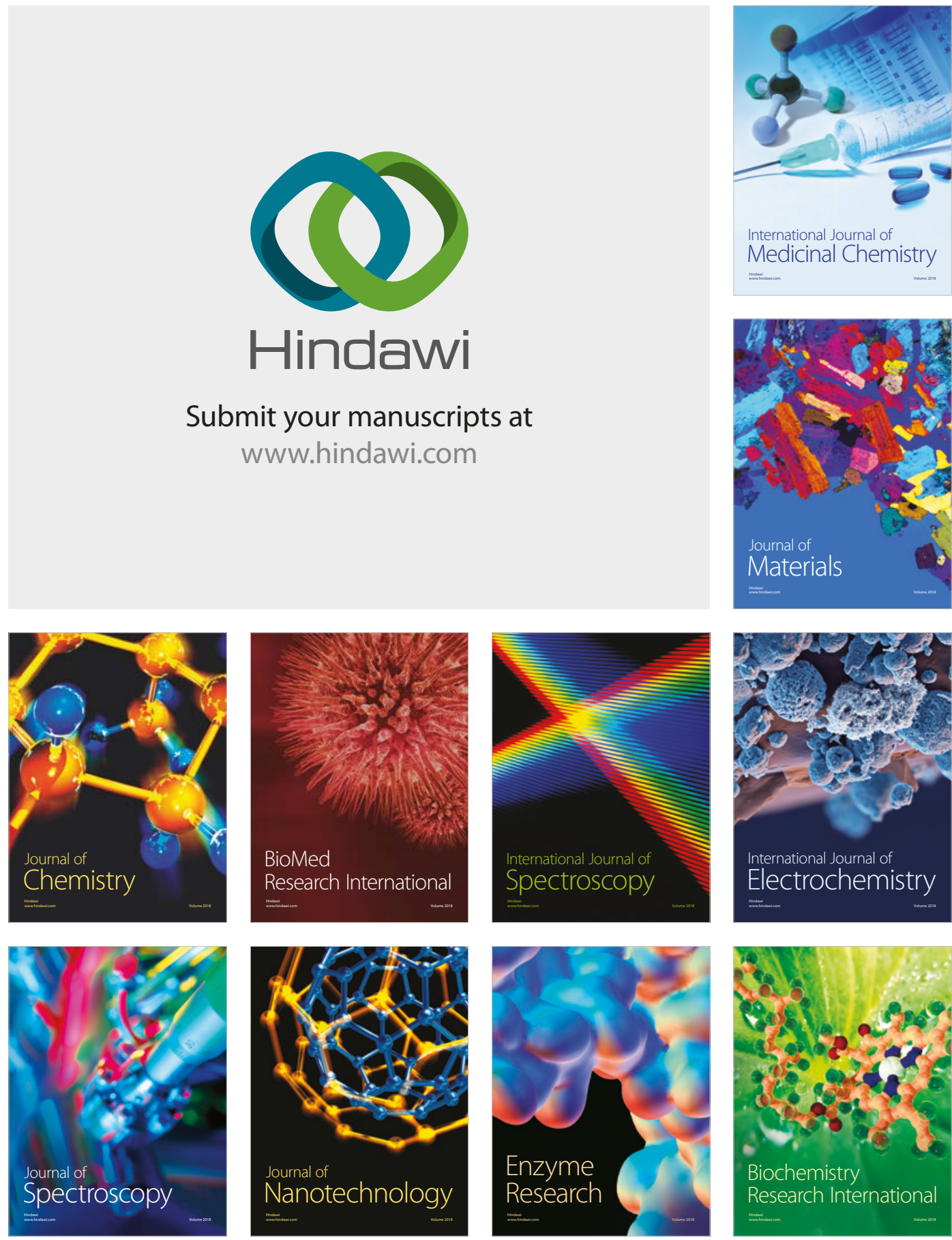
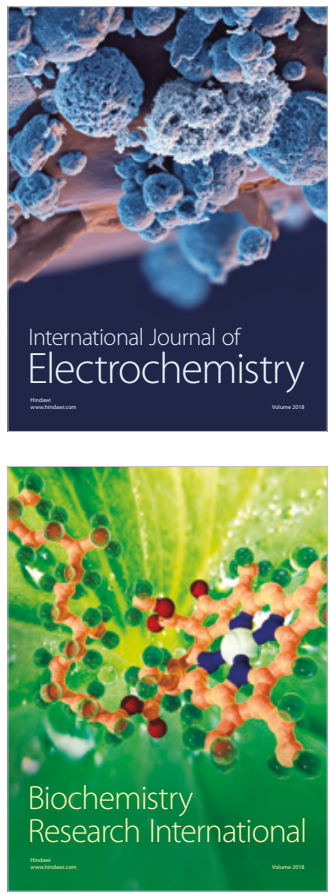